\title{
Hyporheic exchange mechanism driven by flood wave
}

\author{
Dongsheng Liu ${ }^{1}$, Qihao Jiang ${ }^{2}$, Wenqing Shi ${ }^{1}$, Qiuwen Chen ${ }^{1}$, and Jin-Yong Lee ${ }^{3}$ \\ ${ }^{1}$ Nanjing Hydraulic Research Institute \\ ${ }^{2}$ Hohai University \\ ${ }^{3}$ Kangwon National University
}

June 2, 2020

\begin{abstract}
To study the hyporheic exchange driven by a single peak flood-induced water level fluctuation (i.e. flood wave), a method combining numerical simulation with theoretical derivation was proposed based on the Inbuk Stream, Korea, where flooding occurs frequently. The hyporheic exchanges induced by different flood waves were investigated by varying amplitude (A), duration $(\mathrm{T})$, wave type parameter (r), and rising duration (tp), which were adopted from the real-time stream stage fluctuations. Additionally, the idea of constant upstream flood volume (CUFV) condition for flood waves was put forward, and the effects of "Botan" (T/A) and peak number (N) on hyporheic exchange were studied. The results showed that the hyporheic exchange flux (q) was controlled by the water level $\mathrm{h}$ (sine-type) and its change rate $\mathrm{v}$ (cosine-type), and was proportional to the polynomial of them q"[?]" $(\omega[?] \mathrm{h}+\mathrm{v})$, where $\omega$ is the angular frequency of the flood wave. Based on this mechanism, the influence principles on hyporheic exchanges of the typical flood wave parameters (A, T, r and tp) as well as T/A and N under CUFV condition were clarified. The main characteristic variables of hyporheic exchange, which were maximum aquifer storage and residence time, were positively correlated. They also had positive relations to the integral of the flood wave over time, which increased when the wave became higher, wider, rounder and less skewed. However, when CUFV condition was imposed, the residence time was positively correlated with $\mathrm{T} / \mathrm{A}$, whereas the maximum aquifer storage was negatively correlated with $\mathrm{T} / \mathrm{A}$. With the increase in $\mathrm{N}$, water exchanged more frequently and some water returned to the stream early, leading to the slight decrease in maximum aquifer storage and residence time. These findings enriched the theory of hyporheic exchange driven by surface water fluctuation and be of great significance to enhance pollutant degradation in the hyporheic zone downstream of reservoirs.
\end{abstract}

\begin{abstract}
To study the hyporheic exchange driven by a single peak flood-induced water level fluctuation (i.e. flood wave), a method combining numerical simulation with theoretical derivation was proposed based on the Inbuk Stream, Korea, where flooding occurs frequently. The hyporheic exchanges induced by different flood waves were investigated by varying amplitude $(A)$, duration $(T)$, wave type parameter $(r)$, and rising duration $\left(t_{\mathrm{p}}\right)$, which were adopted from the real-time stream stage fluctuations. Additionally, the idea of constant upstream flood volume (CUFV) condition for flood waves was put forward, and the effects of "Botan" $(T / A)$ and peak number $(N)$ on hyporheic exchange were studied. The results showed that the hyporheic exchange flux $(q)$ was controlled by the water level $h$ (sine-type) and its change rate $v$ (cosinetype), and was proportional to the polynomial of them $q \propto(\omega \bullet h+v)$, where $\omega$ is the angular frequency of the flood wave. Based on this mechanism, the influence principles on hyporheic exchanges of the typical flood wave parameters $\left(A, T, r\right.$ and $\left.t_{\mathrm{p}}\right)$ as well as $T / A$ and $N$ under CUFV condition were clarified. The main characteristic variables of hyporheic exchange, which were maximum aquifer storage and residence time, were positively correlated. They also had positive relations to the integral of the flood wave over time, which increased when the wave became higher, wider, rounder and less skewed. However, when CUFV condition was imposed, the residence time was positively correlated with $T / A$, whereas the maximum aquifer storage was negatively correlated with $T / A$. With the increase in $N$, water exchanged more frequently and some
\end{abstract}


water returned to the stream early, leading to the slight decrease in maximum aquifer storage and residence time. These findings enriched the theory of hyporheic exchange driven by surface water fluctuation and be of great significance to enhance pollutant degradation in the hyporheic zone downstream of reservoirs.

Keywords: hyporheic exchange; flood wave; numerical simulation; theoretical derivation

\section{Introduction}

The hyporheic zone is a critical area where mixing of shallow groundwater and surface water occurs in the fluvial system (Hester \& Gooseff, 2010; White, 1993). The important role it plays in maintaining the ecological health of rivers has been repeatedly demonstrated and gradually accepted by the academic community (Findlay, 1995; Marzadri et al., 2013; Storey et al., 1999). There are many factors (Lewandowski et al., 2019) that promote hyporheic exchange (HE). Flood events are important driving forces due to mountain torrents, snow melt, storm events and reservoir operations which commonly occur in natural rivers. Flood-induced water level fluctuation (i.e. flood wave) and associated lateral propagation can change the hydrological situation in the hyporheic zone (Curry et al., 1994; Friesz, 1996), and subsequently promote the transport and transformation of pollutants (Harvey et al., 2013; Kolbjørn Jensen et al., 2017; Roley et al., 2012; Trauth et al., 2018), the reproduction of benthic organisms (Boulton et al., 1998; Holomuzki \& Biggs, 2000; Olsen \& Townsend, 2005) and the growth of vegetation in the riparian zone (Harner \& Stanford, 2003; Mouw et al., 2009). However, large-scale human activities (e.g. damming, river channelization, hard-type bank protection, artificial flow regulation) (Hancock, 2002) can weaken the flood pulse of natural rivers to varying degrees, and may have a substantial impact on the ecological function of the hyporheic zone (Arias et al., 2013; Keizer et al., 2014; Nilsson \& Berggren, 2000). Hence, a better understanding of HE driven by flood wave is key for the healthy river development and restoration of damaged or degraded rivers.

Piezometers were appropriately arranged in a riverbed or riparian zone and some chemical indexes were collected (e.g. Hanrahan, 2008; Jeon et al., 2015) in previous field investigations. The studies showed that the river-aquifer hydraulic gradient responds rapidly to the transient water level fluctuations (Arntzen et al., 2006), and there was a certain quantitative relationship between them (Fritz \& Arntzen, 2007). The HE flux $(q)$ between surface water and groundwater was found to be linearly proportional to the river water level when there is a significant hydrological connection (Cardenas, 2010). However, this is inconsistent with the nonlinear relationship described by Chen et al. (2013). Crosbie et al. (2014) proposed a two square function relationship between $q$ and the river water level. Based on field tests, some studies have quantitatively analyzed the extent of water infiltrating into the aquifer, the corresponding residence time and the spatiotemporal distribution. Their results showed that the magnitude of lateral exchange decreases as the distance from the river increases (e.g. Graham et al., 2015; Liu et al., 2018; Sawyer et al., 2009); however, in the streambed, both the vertical infiltration distance and residence time decrease with proximity to the middle of the river (Gerecht et al., 2011).

Previous numerical simulations indicated that river water fluctuation increase the bank storage and infiltration extent (Chen \& Chen, 2003; Doble et al., 2012; Gu et al., 2012; Maier \& Howard, 2011; Welch et al., 2013; Welch et al., 2015), and enabled the retention of water particles in the aquifer for a long period (Diem et al., 2014; McCallum \& Shanafield, 2016). Siergieiev et al. (2015) analyzed the bank storage and residence time under different flood wave scenarios by constructing a 2-Dimensinal variably saturated model of the bank cross section, and indicated that bank storage increases with wave amplitude and duration, while the ratio of return time to infiltration time is positively related to amplitude and negatively related to duration. Trauth and Fleckenstein (2017) set up a reactive transport groundwater model with a wide range of flood scenarios. Their results showed that the longer the flood duration and the higher the peak discharge, the greater the magnitude of $\mathrm{HE}$ and the higher the reactive efficiency for aerobic respiration as well as denitrification in the hyporheic zone below a natural in-stream gravel bar.

The above studies have highlighted the quantitative relationship between $q$ and the water level. However, few studies have quantified the effect on $q$ of the rate of water level change. In addition, previous numerical simulations focus mainly on the effects of flood wave amplitude $(A)$ and duration $(T)$ on HE (e.g. Chen \& 
Chen, 2003). However, some important wave parameters such as the wave type $(r)$ and rising duration $\left(t_{\mathrm{p}}\right)$, which characterize the roundness and peak position of a wave, have been ignored. Furthermore, there have been few studies about the influences of flood waves on HE under constant upstream flood volume (CUFV) condition, although it is of great value to the ecological operation of a reservoir.

In this study, HEs driven by flood waves was systematically studied. We aim to: (1) reveal the mechanism of superimposed influences from flood-induced water level and its change rate on HE; (2) further investigate the influences of typical flood wave parameters $\left(A, T, r\right.$ and $\left.t_{\mathrm{p}}\right)$ on HE; (3) gain insight to the influences of "Botan" $(T / A)$ and peak number $(N)$ on HE under CUFV condition.

\section{Methods}

\subsection{Model descriptions}

Based on the field investigation in the upper reach of the Inbuk Stream, Korea, we have developed a 2Dimensional finite element flow model using FEFLOW 7.0 (Liu et al., 2009). In this study, we adopt and improved the model to simulate water exchanges across the stream-to-riparian continuum induced by flood waves. Two improvements have been made to the model. First, the free development of seepage was taken into account in the stream-aquifer interface of the model, that is, the original time-varying head condition (Dirichlet) was replaced by the mixed boundary condition that combines the Dirichlet condition with flow constraints, as shown in Fig. 1. Second, the improved model considered the poroelastic response of the aquifer media caused by the change of hydrostatic load and hence the corresponding governing equation was modified, similar to Reeves et al. (2000), Gardner and Wilson (2006) and Boutt (2010). Considering the above improvements, some input parameters of the model, including the maximum saturation $\left(S_{\mathrm{s}}\right)$, effective porosity $\left(n_{\mathrm{e}}\right)$ and specific storage $\left(S_{0}\right)$, were re-calibrated (Table 1$)$. The $S_{\mathrm{s}}$ was re-calibrated because the mixed boundary conditions of the model would avoid the infiltration of unsaturated boundary nodes and lead to the relative decrease in maximum saturation of the VG model involved in the Richards' equation. Then e and $S_{0}$ were re-calibrated because of the compressibility of fluid and solid media as well as the poroelastic response. The input parameters of the improved model are shown in Table 1.

Figure 1 should be here

Table 1 should be here

\subsection{Flood wave scenarios}

Due to seasonal flood events and reservoir operations, the stage of the Inbuk Stream at the investigation site fluctuates approximately sinusoidally, with the maximum amplitude and duration reaching $1 \mathrm{~m}$ and $10 \mathrm{~d}$, respectively (Liu et al., 2019). To better understand the stream-aquifer water exchanges driven by different flood wave parameters, a variety of flood wave scenarios were designed (black square frame in Fig. 2). To accomplish this, the values of $A, T, r$ and $t_{\mathrm{p}}$ were varied, and the range of each parameter was roughly determined by the stream stage measurements obtained between 2014 and 2016.

Additionally, a variety of flood waves of different $T$ / Aand $N$ were envisaged (red square frame in Fig. 2) by assuming CUFV condition, saying keep the integral of flow discharge overtime in the upstream of the investigation site constant. The cross-section discharge is an exponential function (exponent $=8 / 3$ ) of the corresponding water depth (Liu et al., 2019); however, in this study we established a linear relationship (i.e. exponent $=1$ ) between the cross-section discharge somewhere in the upstream of the site and the water depth at the specific site. Through this way, we could design different flood waves under CUFV condition by controlling the integral of the flood wave over time at the site.

Figure 2 should be here

\subsection{Estimation of hyporheic metrics through model}

The characteristic variables and calculation methods for quantifying HE were given in the following: 
(1) HE flux between surface water and groundwater per unit length of stream is obtained by integrating the normal velocity along the stream-aquifer interface:

$$
\mathrm{q}=\int_{0}^{\mathrm{l}} \mathrm{v}_{\mathrm{n}} \mathrm{dl}(1)
$$

where $q$ is HE flux, $\mathrm{m}^{2} / \mathrm{d} ; v_{\mathrm{n}}$ is the normal velocity, $\mathrm{m} / \mathrm{d} ; l$ is the length of stream-aquifer interface, $\mathrm{m}$.

(2) The balance between surface water and groundwater is obtained by integrating $q$ with time, which is defined as aquifer storage:

$$
\overline{\mathrm{Q}=\int_{0}^{\mathrm{t}} \mathrm{qdt}(2)}
$$

where $Q$ is aquifer storage, $\mathrm{m}^{2} ; t$ is time, $\mathrm{d}$.

(3) The duration of the graph of $Q$ is defined as residence time $(R T$, d) (Siergieiev et al., 2015).

(4) The ratio of return time to infiltration time $\left(t_{\mathrm{R}} / t_{\mathrm{F}}\right)$ is defined according to the graph of $Q .\left(t_{\mathrm{F}}, \mathrm{d}\right)$ refers to the time required for $Q$ to rise from zero to its maximum, while $\left(t_{\mathrm{R}}, \mathrm{d}\right)$ refers to the time required for $Q$ to decrease from its maximum to zero (Siergieiev et al., 2015).

\subsection{Derivation of HE flux in relation to the polynomial of water level and its change rate}

Assuming that (1) the flood wave at the site was approximately sinusoidal; (2) the variation of wave amplitude was much smaller than the thickness of the aquifer; and (3) the aquifer was relatively homogeneous and had good permeability, the water head within the riparian aquifer in response to the flood wave can be approximately obtained as follows (Singh, 2004):

$$
\overline{\mathrm{h}(\mathrm{x}, \mathrm{t})=\operatorname{Aexp}\left(-\mathrm{x} \sqrt{\frac{\omega}{2 \mathrm{D}}}\right) \times \sin \left(-\mathrm{x} \sqrt{\frac{\omega}{2 \mathrm{D}}}+\omega \tau+\varphi\right) \quad(3)}
$$

where $h$ is hydraulic head, $\mathrm{m} ; x$ is distance, $\mathrm{m}$; $t$ is time, $\mathrm{d} ; D$ is hydraulic diffusivity, $\mathrm{m}^{2} / \mathrm{d} ; A$ is the amplitude, $\mathrm{m} ; \omega$ is the angular frequency, $1 / \mathrm{d} ; \varphi$ is the phrase, - .

The $q$ between the stream and aquifer is as follows:

$$
\overline{\mathrm{q}(\mathrm{t})=-\mathrm{Kb} \frac{\partial \mathrm{h}(\mathrm{x}, \mathrm{t}) / \mathrm{x}=0}{\partial \mathrm{x}}(4)}
$$

where $K$ is the hydraulic conductivity, $\mathrm{m} / \mathrm{d} ; b$ is the saturated aquifer thickness, $\mathrm{m}$.

Substituting (3) into (4) gives:

$$
\mathrm{q}(\mathrm{t})=\mathrm{KbA} \sqrt{\frac{\omega}{2 \mathrm{D}}}[\sin (\omega \mathrm{t}+\varphi)+\cos (\omega \mathrm{t}+\varphi)]
$$

At the stream-aquifer interface (i.e. $x=0$ ), the aquifer head is the flood wave $(h)$ :

$$
\overline{\mathrm{h}(\mathrm{x}=0, \mathrm{t})=\mathrm{A} \sin (\omega \mathrm{t}+\varphi) \quad(6)}
$$

The rate of water level change $(v)$ can be obtained by deriving the water level: 


$$
\underline{\mathrm{v}(\mathrm{t})=\frac{\partial \mathrm{h}(\mathrm{x}=0, \mathrm{t})}{\partial \mathrm{t}}=\mathrm{A} \omega \cos (\omega \mathrm{t}+\varphi)}
$$

Hence, $q$ expressed as the variation of flood-induced water level (6) and its change rate (7) is as follows:

$$
\mathrm{q}(\mathrm{t})=\frac{\mathrm{K} \beta}{\sqrt{2 \omega \Delta}}(\omega \mathrm{h}+\mathrm{v}) \quad(8)
$$

\section{Results}

\subsection{Influence of a single peak flood wave on $\mathrm{HE}$}

The dynamic change of $q$ (Fig. 3a) could be divided into five stages, which correspond to OA, AB, BC, CD and $\mathrm{DE}$ on the flood wave of the base case. The OA $(0<t<0.5 \mathrm{~d})$ corresponded to the initial stream stage before the flood event. Because the Inbuk Stream was recharged by groundwater all year round, qin this period remained an unchanged negative value (Jeon et al., 2015), that is, groundwater recharged the stream at a constant rate along the stream-aquifer interface (Fig. 3b). The stream-groundwater balance increased negatively from aquifer to stream (Fig. 3c). The $\mathrm{AB}$ represented a period $(0.5<t<0.95 \mathrm{~d})$ of rising stream stage, in which the stream continuously recharged groundwater, with the magnitude of $q$ gradually increasing to the maximum $\left(q^{+}{ }_{\text {max }}\right)$. Accordingly, $Q$ increased from negative to positive. During the BC, the stream stage first rose to the peak and then fell down $(0.95<t<2.15 \mathrm{~d})$. The stream kept recharging groundwater; however, the magnitude of $q$ gradually decreased from $q{ }^{+}{ }_{\max }$ to zero. As the result, $Q$ kept increasing and reached the maximum $(Q$ max $)$. The stream stage continued falling and approached the initial stage during $\mathrm{CD}(2.15<t<3.1 \mathrm{~d})$. The groundwater began discharging into the stream again, with the magnitude of $q$ gradually reaching the maximum in the negative direction $\left(\mid q^{-}\right.$max $\left.\mid\right)$. At the same time, $Q$ decreased gradually due to the backflow of groundwater. The stream stage in DE $(3.1<t<20 \mathrm{~d})$ included a short falling limb and a long period of initial stage. Groundwater was released back into the stream over a longer period after the flood event, with $q$ and $Q$ decreasing to zero. The negative value of $Q$ at the end of this period was due to the gaining condition of the stream at the site.

\section{Figure 3 should be here}

By comparing (a) and (b) of Fig. 3, it could be seen that $q$ was in general positively correlated with the flood wave, but the positive and negative extremes (i.e. $q^{+}{ }_{\max },\left|q^{-}{ }_{\max }\right|$ ) appeared before the peak and the initial value of the stream stage, respectively. This finding was consistent with previous studies (Chen and Chen, 2003; McCallum et al., 2010; Doble et al., 2012; Gu et al., 2012; Siergieiev et al., 2015; McCallum and Shanafield, 2016; Shuai et al., 2017); however, previous explanations to the mechanism of this phenomenon are insufficient. Therefore, the response mechanism of $q$ to a flood wave was further investigated by theoretical derivation in this study.

It could be seen from Formula (8) that $q$ has a linear relationship with the polynomial " $\omega \eta+v$ ". When the flood wave first rose and then fell in a sinusoidal manner, $v$ first decreased and then increased in a cosine manner. The superposition of the two processes could well explain why $q^{+}{ }_{\text {max }}$ and $\left|q^{-}{ }_{\text {max }}\right|$ appeared before the peak and initial value of the flood wave, respectively. In other words, although the flood wave had not yet reached its peak, the value of the polynomial " $\omega \eta+v$ "had reached its maximum, which made $q$ reach $q^{+}{ }_{\max }$. The same was hold for why $\left|q^{-}{ }_{\max }\right|$ occurred prior to the initial water level. In addition, the occurrence time of $q^{+}{ }_{\max }$ and $\left|q^{-}{ }_{\max }\right|$ were close to that of the peak or initial flood wave value, because the influence of $h$ on $q$ was much larger than that of $v$ : the flood wave of the base case in Fig. 3 (i.e. $T=$ $3 \mathrm{~d}) \operatorname{caused} \omega(=2 \mathrm{pi} / \mathrm{T})$ to be greater than 1 .

According to Formula (8), we randomly selected a flood wave as an example and showed the variations of the flood wave and its change rate as well as their polynomial " $\omega \eta+v "$ through Fig. 4 . The moments of t1 and t2 corresponded to the two inflection points of the polynomial " $\omega \eta+v "$. It could be seen that they appeared before the peak and initial value of the flood wave, respectively, which further verified the findings from the numerical simulation (Fig. 3). 


\subsection{Influences of typical flood wave parameters on HE}

The $q^{{ }^{+}}{ }_{\max },|q|^{-}$max and $Q$ max showed increasing trends with $A$ (Fig. 5a1, a2); with each $50 \%$ increase in $A, Q$ max increased by about $0.354 \mathrm{~m}^{2}$. The increase of $A$ signifies that at any time, the height of the water level and its change rate have increased, and thus $q$ and $Q$ increased correspondingly, based on formula (8). The change of $R T$ was the same as that of $Q$ max. When $A$ increased by $50 \%, R T$ increased by about 2.21 days. The ratiot $t_{\mathrm{R}} / t_{\mathrm{F}}$ increased with $A$, mainly because $t_{\mathrm{R}}$ increased with $A$, while $t_{\mathrm{F}}$ changed only slightly (Fig. 5a2). In order to clearly show the variation of characteristic HE variables with the flood wave parameters, the main results are summarized in Table 2.

The $q^{+}{ }_{\max }$ and $|q|^{-}$max decreased with $T$, and their occurrence times were postponed accordingly (Fig. 5b1), while $Q$ max increased with $T$ and its occurrence time was postponed, too (Fig. 5b2). $Q$ max increased by about $0.233 \mathrm{~m}^{2}$ when $T$ increased by $50 \%$. An increase in $T$ signifies the water level rising or falling slowly, as a result, $q^{+}{ }_{\max }$ and $|q|^{-}$max decreased accordingly. The occurrence times of $q{ }^{+}{ }_{\max }$ and $|q|^{-}$max were postponed with increasing $T$, because of the delayed appearance of the wave peak. $Q$ max increased with $T$ because a larger $T$ indicates a longer period of stream water recharging the groundwater. $R T$ was proportional to $Q$ max , and the averaged increase in $R T$ was 2.18 days for each $50 \%$ increase in $T$. However, $t$ $\mathrm{R} / t_{\mathrm{F}}$ decreased with $T$, mainly because $t_{\mathrm{R}}$ increased less than $t_{\mathrm{F}}$ (Fig. 5b2).

The $q^{+}{ }_{\text {max }}$ increased with $r$ and its occurrence time was postponed; on the contrary, $|q|^{-}$max decreased with $r$ and its occurrence time was early (Fig. 5c1). The behavior of $Q$ max was the same as $|q|^{-}$max (Fig. 5c2). The $Q$ max decreased by about $0.128 \mathrm{~m}^{2}$ as $r$ increased by $50 \%$. When rincreases, the flood wave becomes "thin" (Fig. 2) and the overall water level decreases, which caused the maximum recharge of stream water to groundwater $\left(Q_{\max }\right)$ to decrease accordingly. The thinner the flood wave, the larger the change rate of water level around the wave peak, and the smaller the change rate of water level around the initial value of the water level. Therefore, from formula (8), $q^{+}{ }_{\max }$ and $|q|^{-}$max increased and decreased with increasing $r$, respectively. Furthermore, the thinner the flood wave, the later the water level rises to a certain height, and the earlier the water level falls to a certain height. This phenomenon can better explain why $q^{+}{ }_{\max }$ and $\mid q$ $I^{-}$max occurred later and earlier, with the increase of $r$. In addition, $R T$ decreased 1.01 days on average, for each $50 \%$ increase in $r$. However, $t_{\mathrm{R}} / t_{\mathrm{F}}$ increased with $r$, mainly because $t_{\mathrm{R}}$ decreased less than $t_{\mathrm{F}}$ (Fig. $5 \mathrm{c} 2$ ).

The $q^{+}{ }_{\max },|q|^{-}$max showed decreasing and increasing trends with $t_{\mathrm{p}}$, respectively, and the occurrence times of both were postponed (Fig. 5d1). $Q$ max increased with $t_{\mathrm{p}}$, and its occurrence time was also postponed (Fig. 5d2). $Q$ max increased by $0.0933 \mathrm{~m}^{2}$ for each $50 \%$ increase in $t_{\mathrm{p}}$. An increase of $t_{\mathrm{p}}$ (i.e. wave crest is less skew) (Fig. 2) signified that the rate of water level change decreased during the rising limb and increased during the falling limb of the same water level, which resulted in the corresponding decrease and increase of $q^{+}{ }_{\max }$ and $|q|^{-}{ }_{\max }$, respectively. Similarly, with the increase of $t_{\mathrm{p}}$, the moment of the water level rising or falling to a certain height were delayed, which explained why the occurrence time of $q{ }^{+}{ }_{\max }$ and $|q|^{-}$max were postponed. In addition, $Q$ max increased with $t_{\mathrm{p}}$, which was caused by the corresponding increase of the overall water level. For each $50 \%$ increase in $t_{\mathrm{p}}$, the average increase in $R T$ was 0.45 days. However, $t$ ${ }_{\mathrm{R}} / t_{\mathrm{F}}$ decreased with $t_{\mathrm{p}}$ as $t_{\mathrm{R}}$ increased less than $t_{\mathrm{F}}$ (Fig. 5d2).

Table 2 should be here

Figure 5 should be here

\subsection{Influences of flood waves on HE under CUFV condition}

Under CUFV condition, with the increase of $T / A$, the flood wave became flat and wide (Fig. 2), and $q$ ${ }^{+}{ }_{\max },|q|^{-}{ }_{\max }$, as well as $Q$ max showed decreasing trends with postponed occurrence time (Fig. 6a1, a2, and Table 3). $Q$ max decreased by about $0.138 \mathrm{~m}^{2}$ when $T / A$ increased by 5 (dimensionless). Compared Fig. 5b1 with Fig. 6a1, it could be seen that the change of $q$ with $T / A$ was similar to that of $q$ with $T$. The only difference was that the effect of $T / A$ on $q$ was greater. $Q$ max , however, showed the opposite trend 
in response to changes in $T / A$ and $T$ (Fig. $5 \mathrm{~b} 2$ with Fig. 6a2), mainly because the change in $T / A$ was accompanied by a change in $A$ in the opposite direction. According to previous studies (e.g. Liu et al., 2019; Mahmood et al., 2019), the influence weight of $A$ on $Q$ max is significantly greater than that of $T$. Thus, when $T$ and $A$ varied by the same amount but in opposite directions, the superposition effects of the two would make the change trend of $Q$ max follow with that of $A$. In addition, the change trends of $R T$ and $Q$ max with $T$ / $A$ were opposite, which was different from the same changing behaviors of $R T$ and $Q$ max with the other flood wave parameters. For each increase of 5 (dimensionless) in $T / A, R T$ increased on average by 0.301 days. $t_{\mathrm{R}} / t_{\mathrm{F}}$ decreased with $T / A$, which could be explained by Fig. $6 \mathrm{a} 2$, that is, $t_{\mathrm{R}}$ and $t_{\mathrm{F}}$ increased simultaneously with $T / A$, but the former increased less than the latter. To demonstrate the differences between conditions of constant upstream flood volume and non-constant upstream flood volume, the results of this study were compared with those from Siergieiev et al. (2015), as shown in Fig. 7. It was found that the change trends of $R T$ or $t_{\mathrm{R}} / t_{\mathrm{F}}$ were basically similar $(T / A<50)$, while the trends of $Q \max$ were completely different.

Figure 6 should be here

Figure 7 should be here

Table 3 should be here

Under CUFV condition, $q^{+}{ }_{\max }$ and $|q|^{-}$max showed increasing trends with an increase in $N$ of the flood wave, and their occurrence times were early and delayed, respectively (Fig. 6b1, Table 3). This was because the greater the $N$, the thinner the waveforms corresponded to the first and last peaks (Fig. 2), and the greater the rate of water level change under the same water level, the earlier the first peak appeared and the later the water level reached the initial water level. However, $Q$ max decreased as $N$ increased, and the occurrence time was delayed (Fig. 6b2, Table 3). $Q$ max decreased by about $0.0275 \mathrm{~m}^{2}$ when $N$ increased by 1 .This was mainly because with the increase in $N$, the water traveled in and out of the aquifer more frequently. Part of the water returned to the stream in advance, resulting in a smaller range of water infiltration (i.e. smaller $Q_{\max }$ ), and a longer time taken to reach the maximum range (i.e. delayed $Q$ max). It should be noted that previous studies (e.g. Gu et al., 2012) have shown that the surface water infiltration range is positively correlated with $Q$ max. In addition, the change behaviors of $R T$ and $Q$ max were generally similar, showing decreasing trends with $N$. The average $R T$ decreased by about 0.675 days as $N$ increased by 1 . The $t_{\mathrm{R}} / t_{\mathrm{F}}$ showed a decreasing trend with $N$, due to the decrease in $t_{\mathrm{R}}$ and increase in $t_{\mathrm{F}}$ (Fig. 6b2). $t_{\mathrm{R}}$ decreased with $N$ because the greater the $N$, the more frequently the water flowed back to the stream. This made part of the water return to the stream early, thereby shortened the return time of the whole water body.

\section{Discussion}

\subsection{Mechanism of flood wave affecting HE}

The dynamic process of $q$, between the stream and aquifer, was not only affected by variation of the stream water level, but also by the rate of variation. This was due to the fact that groundwater moves rather slowly compared to open water flow. When the stream water level rose or fell to a certain height with different rates, the response time left for groundwater would be different and the corresponding groundwater level at such moment would never be the same, resulting in variations of the surface water-groundwater hydraulic gradient and consequently the $q$ values. Hence, we concluded that $q$ was proportional to the polynomial of water level and its change rate: $q \propto(\omega \bullet h+v)$, where $\omega$ is the angular frequency of the flood wave. The rate of water level change was less influential on $q$ than that of the water level itself due to the influence weight of water level $(\omega=2 \mathrm{pi} / \mathrm{T})$ was generally greater than 1 . This was also why many studies (e.g. Chen \& Chen, 2003; Gu et al., 2012; Shuai et al., 2017) have concluded that $q$ is positively correlated with the water level as a whole.

Typical flood wave parameters $\left(A, T, r, t_{\mathrm{p}}\right)$ characterized the height, width, roundness and skewness of a wave, respectively. Essentially, an increase in $A$ signifies an increase in water level and its change rate at any time; an increase in $T$ mainly reduces the overall change rate of the water level; an increase in $r$ leads to an 
increase of change rate near the wave peak and a decrease of change rate near the initial value of the wave; increasing $t_{\mathrm{p}}$ has the opposite effect to increasing $r$. In summary, different parameters reflected the water level and its rate of change with different regularities throughout the duration of the flood wave, thus leading to the very different influences on $q$. Similarly, under CUFV condition the increase in $T / A$ is equivalent to the simultaneous increase in $T$ and decrease in $A$. Therefore, the influence mechanism of $T / A$ on $q$ was similar to that of $T$, but its influence was greater. The effect on qof increasing $N$ was equivalent to shortening the duration of each pulse and increasing the overall change rate of water level accordingly.

The $Q$ max induced by a flood wave was mainly controlled by the wave duration and the average water level height, showing positive correlations with both (e.g. Liu et al., 2018). When the flood wave duration was constant, the higher $(A /)$, rounder $\left(r\right.$ and less skewed $\left(t_{\mathrm{p}} /\right)$ the flood wave, the larger the integral of the flood wave over time, resulting in a larger $Q$ max. $R T$ was generally positively correlated with $Q$ max (e.g. Siergieiev et al., 2015), but this relationship was not valid for the flood wave under CUFV condition. Fig. 7 showed that the change trends of $R T$ and $Q$ max were completely different under CUFV condition. The main reason was that $T$ and $A$ were related variables under CUFV condition. An increase in $T$ would inevitably lead to a decrease in $A$, and $A$ was dominant to $Q$ max.

\subsection{Implications of flood waves under CUFV condition on water environment}

Flood waves enhance the interaction between the surface water and groundwater, and greatly promote the migration and transformation of pollutants in the river ecosystem (e.g. Boutt and Fleming, 2009; Smith et al., 2009). The nitrogen cycle provides a good example: when the river water level rises, it carries abundant oxygen, ammonia, nitrogen, and nitrate into the hyporheic zone, accompanied by the processes of nitrification and aerobic respiration; as the water level falls, groundwater flows back into the river, providing an anaerobic environment for denitrification. During the whole nitrogen cycle, ammonia and nitrate in the river system are converted into $\mathrm{N}_{2}$ and released, thus realizing nitrogen load reduction.

From the hydrodynamic point of view, the main factors affecting nitrogen removal within the hyporheic zone are $Q$ max and $R T$ (e.g. Gu et al., 2012; Naranjo et al., 2015). The former controls the total amount of nitrogen carried into the aquifer through water infiltration, while the latter controls the duration of reaction time of all solutes. Obviously, the greater the $Q$ max and $R T$ are, the better the nitrogen removal effect is. However, according to this study, $Q$ max and $R T$ could not be increased simultaneously under CUFV condition. In such a case, when the flood wave is designed to be flat and wide (i.e. larger $T / A$ ), nitrogen removal is limited by $Q$ max , and vice versa, by $R T$.

Therefore, the capacity for nitrogen removal of the hyporheic zone first increases and then decreases with an increase of $T / A$ under CUFV condition. There must be an optimal $T / A$ (i.e. inflexion point) that can maximize the nitrogen removal capacity. The optimal $T / A$ may be related to the depth and width of the actual river, which will be studied in our future work. In addition, under CUFV condition, although increasing $N$ reduces $Q$ max and $R T$, it would improve the nitrogen removal capacity of the hyporheic zone. This was because an increase in $N$ could enhance the chemical reaction by promoting the physical mixing of the surface water and groundwater solutes. Such physical process may play a dominant role, because $Q$ max and $R T$ decreased slightly with an increase in $N$, and deserve further investigation.

The study of HE under CUFV condition could be of great scientific and practical significance to the operation of upstream reservoirs, that is, under the premise of constant reservoir capacity, downstream pollutant degradation within the hyporheic zone can be maximized by regulating the reservoir discharge mode.

\section{Conclusions}

A systematic study was conducted on HEs driven by flood waves in a riparian zone mainly through numerical simulations. The main conclusions were summarized as follows:

(1) At any time within the duration of the flood wave, the stream-aquifer $q$ is affected by the superposition of water level $h$ (sine-type) and its change rate $v$ (cosine-type), and is proportional to the polynomial of them: $q$ $\propto(\omega \bullet h+v)$ The weight of influence is determined by $\omega$ (i.e. 2 pi/T), the angular frequency of a flood wave. 
(2) The variations of different flood wave parameters essentially reflect the different performances of water level change and its change rate. The maximum aquifer storage and residence time are mainly controlled by the integral of the flood wave over time, which increases as the wave becomes high, wide, round, and less skewed.

(3) Under CUFV condition, the larger $T / A$, the smaller the maximum aquifer storage (dominated by $A$ ), but the longer the residence time (dominated by $T$ ). With the increase in $N$, water exchanges more frequently and some water returns to the stream early, leading to the decrease in maximum aquifer storage and residence time.

The study provided important understandings to the HE mechanism driven by surface water level fluctuations. In particular, the investigation of HE under CUFV condition offered a significant guidance to enhance pollutant degradation in hyporheic zones downstream of reservoirs.

\section{Acknowledgments}

This work is supported by the National Research Foundation of Korea (NRF) that funded by the Korea government (MSIT) (No.NRF-2015R1A4A1041105), and partly funded by the key projects of NHRI (No.Y919005, No.Y920012) and 66th China Postdoctoral Science Foundation (2019M661882) Helmholtz Centre for Environmental Research - UFZ is acknowledged for providing a free license for FEFLOW 7.0.

\section{Data Availability Statement}

The data that support the findings of this study are available from the authors, including the model calculated data and statistics, which can be seen in the following links (extraction code: q35d):https://pan.baidu.com/s/1AWI5ofEXqyS6yBQcqaSOww.

\section{References}

Arias, M. E., Cochrane, T. A., Norton, D., Killeen, T. J., \& Khon, P., 2013. The flood pulse as the underlying driver of vegetation in the largest wetland and fishery of the Mekong Basin. Ambio, 42(7), 864-876.

Arntzen, E. V., Geist, D. R., \& Dresel, P. E., 2006. Effects of fluctuating river flow on groundwater/surface water mixing in the hyporheic zone of a regulated, large cobble bed river. River Research and Applications, 22(8), 937-946.

Boulton, A. J., Findlay, S., Marmonier, P., Stanley, E. H., \& Valett, H. M., 1998. The functional significance of the hyporheic zone in streams and rivers. Annual Review of Ecology and Systematics, 29(1), 59-81.

Boutt D. F., Fleming B. J., 2009. Implications of anthropogenic river stage fluctuations on mass transport in a valley fill aquifer. Water Resources Research, 45(4), 546-550.

Boutt D. F., 2010. Poroelastic loading of an aquifer due to upstream dam releases. Groundwater, 48(4), 580-592.

Cardenas, M. B., 2010. Lessons from and assessment of Boussinesq aquifer modeling of a large fluvial island in a dam-regulated river. Advances in Water Resources, 33(11), 1359-1366.

Chen, X., \& Chen, X., 2003. Stream water infiltration, bank storage, and storage zone changes due to stream-stage fluctuations. Journal of Hydrology, 280(1-4), 246-264.

Chen, W., Huang, C., Chang, M., Chang, P., \& Lu, H., 2013. The impact of floods on infiltration rates in a disconnected stream. Water Resources Research, 49(12), 7887-7899.

Crosbie, R. S., Taylor, A. R., Davis, A. C., Lamontagne, S., \& Munday, T., 2014. Evaluation of infiltration from losing-disconnected rivers using a geophysical characterisation of the riverbed and a simplified infiltration model. Journal of Hydrology, 508, 102-113. 
Curry, R. A., Gehrels, J., Noakes, D. L., \& Swainson, R., 1994. Effects of river flow fluctuations on groundwater discharge through brook trout, Salvelinus fontinalis, spawning and incubation habitats. Hydrobiologia, $277(2), 121-134$.

Diem, S., Renard, P., \& Schirmer, M., 2014. Assessing the effect of different river water level interpolation schemes on modeled groundwater residence times. Journal of Hydrology, 510, 393-402.

Doble, R., Brunner, P., McCallum, J., \& Cook, P. G., 2012. An analysis of river bank slope and unsaturated flow effects on bank storage. Groundwater, 50(1), 77-86.

Findlay, S., 1995. Importance of surface-subsurface exchange in stream ecosystems: The hyporheic zone. Limnology and oceanography, 40(1), 159-164.

Friesz, P. J., 1996. Geohydrology of stratified drift and streamflow in the Deerfield River Basin, northwestern Massachusetts: US Department of the Interior, US Geological Survey.

Fritz, B. G., \& Arntzen, E. V., 2007. Effect of rapidly changing river stage on uranium flux through the hyporheic zone. Groundwater, 45(6), 753-760.

Gardner L. R., Wilson, A. M., 2006. Comparison of four numerical models for simulating seepage from salt marsh sediments. Estuarine, Coastal and Shelf Science, 69(3-4), 427-437.

Gerecht, K. E., Cardenas, M. B., Guswa, A. J., Sawyer, A. H., Nowinski, J. D., \& Swanson, T. E., 2011. Dynamics of hyporheic flow and heat transport across a bed-to-bank continuum in a large regulated river. Water Resources Research, 47(3).

Graham, P. W., Andersen, M., McCabe, M., Ajami, H., Baker, A., \& Acworth, I., 2015. To what extent do long-duration high-volume dam releases influence river-aquifer interactions? A case study in New South Wales, Australia. Hydrogeology Journal, 23(2), 319-334.

Gu, C., Anderson, W., \& Maggi, F., 2012. Riparian biogeochemical hot moments induced by stream fluctuations. Water Resources Research, 48(9).

Hancock, P. J., 2002. Human impacts on the stream-groundwater exchange zone. Environmental management, 29(6), 763-781.

Hanrahan, T. P., 2008. Effects of river discharge on hyporheic exchange flows in salmon spawning areas of a large gravel-bed river. Hydrological Processes, 22(1), 127-141.

Harner, M. J., \& Stanford, J. A., 2003. Differences in cottonwood growth between a losing and a gaining reach of an alluvial floodplain. Ecology, 84(6), 1453-1458.

Harvey, J. W., Böhlke, J. K., Voytek, M. A., Scott, D., \& Tobias, C. R., 2013. Hyporheic zone denitrification: Controls on effective reaction depth and contribution to whole-stream mass balance. Water Resources Research, 49(10), 6298-6316.

Hester, E. T., \& Gooseff, M. N., 2010. Moving beyond the banks: hyporheic restoration is fundamental to restoring ecological services and functions of streams. Environmental Science \& Technology, 44(5), 1521-1525.

Holomuzki, J. R., \& Biggs, B. J.,2000. Taxon-specific responses to high-flow disturbance in streams: implications for population persistence. Journal of the North American Benthological Society, 19(4), 670-679.

Jeon, W. H., Lee, J. Y., Cheong, W. Y., Park, Y. H., Oh, S. H., Eum, D. H., \& Park, J. Y., 2015. A multi-method approach revealing the groundwater-stream water interaction in the Inbuk stream, Korea. Geosciences Journal, 19(2), 325-340.

Keizer, F., Schot, P., Okruszko, T., Chormański, J., Kardel, I., \& Wassen, M., 2014. A new look at the flood pulse concept: the (ir) relevance of the moving littoral in temperate zone rivers. Ecological Engineering, 64, 85-99. 
Kolbjørn Jensen, J., Engesgaard, P., Johnsen, A. R., Marti, V., \& Nilsson, B., 2017. Hydrological mediated denitrification in groundwater below a seasonal flooded restored riparian zone. Water Resources Research, 53(3), 2074-2094.

Lewandowski, J., Arnon, S., Banks, E., Batelaan, O., Betterle, A., Broecker, T., .. \& \& Wu, L., 2019. Is the Hyporheic Zone Relevant beyond the Scientific Community. Water, 11(11).

Liu, D., Zhao, J., Chen, X., Li, Y., Weiyan, S., \& Feng, M., 2018. Dynamic processes of hyporheic exchange and temperature distribution in the riparian zone in response to dam-induced water fluctuations. Geosciences Journal, 1-11.

Liu, D., Zhao, J., Jeon, W. H., \& Lee, J. Y., 2019. Solute dynamics across the stream-to-riparian continuum under different flood waves. Hydrological Processes, 33(20), 2627-2641.

Mahmood, M. N., Schmidt, C., Fleckenstein, J. H., \& Trauth, N., 2019. Modeling the impact of stream discharge events on riparian solute dynamics. Groundwater, 57(1), 140-152.

Maier, H. S., \& Howard, K. W., 2011. Influence of oscillating flow on hyporheic zone development. Groundwater, 49(6), 830-844.

Marzadri, A., Tonina, D., \& Bellin, A., 2013. Quantifying the importance of daily stream water temperature fluctuations on the hyporheic thermal regime: Implication for dissolved oxygen dynamics. Journal of Hydrology, 507, 241-248.

McCallum, J. L., \& Shanafield, M., 2016. Residence times of stream-groundwater exchanges due to transient stream stage fluctuations. Water Resources Research, 52(3), 2059-2073.

Mouw, J. E., Stanford, J. A., \& Alaback, P. B., 2009. Influences of flooding and hyporheic exchange on floodplain plant richness and productivity. River Research and Applications, 25(8), 929-945.

Naranjo R. C., Niswonger R. G., Davis C. J., 2015. Mixing effects on nitrogen and oxygen concentrations and the relationship to mean residence time in a hyporheic zone of a riffle-pool sequence. Water Resources Researchz, 51(9), 7202-7217.

Nilsson, C., \& Berggren, K., 2000. Alterations of Riparian Ecosystems Caused by River Regulation: Dam operations have caused global-scale ecological changes in riparian ecosystems. How to protect river environments and human needs of rivers remains one of the most important questions of our time. AIBS Bulletin, 50(9), 783-792.

Olsen, D. A., \& Townsend, C. R., 2005. Flood effects on invertebrates, sediments and particulate organic matter in the hyporheic zone of a gravel-bed stream. Freshwater Biology, 50(5), 839-853.

Reeves H. W.,Thibodeau P. M., Underwood R. G., et al., 2000.Incorporation of total stress changes into the ground water model SUTRA. Groundwater, 38(1), 89-98.

Sawyer, H. A., Cardenas, M. B., Bomar, A., \& Mackey, M., 2009. Impact of dam operations on hyporheic exchange in the riparian zone of a regulated river. Hydrological Processes, 23(15), 2129-2137.

Singh, S.K., 2004. Aquifer response to sinusoidal or arbitrary stage of semipervious stream. Journal of Hydraulic Engineering, 130, 1108-1118.

Shuai P, Cardenas M B, Knappett P S K, et al., 2017. Denitrification in the banks of fluctuating rivers: The effects of river stage amplitude, sediment hydraulic conductivity and dispersivity, and ambient groundwater flow. Water Resources Research, 53(9), 7951-7967.

Siergieiev, D., Ehlert, L., Reimann, T., Lundberg, A., \& Liedl, R., 2015. Modelling hyporheic processes for regulated rivers under transient hydrological and hydrogeological conditions. Hydrology and Earth System Sciences, 19(1), 329. 
Smith J. W. N., Surridge B. W. J., Haxton T. H., \& Lerner, D. N., 2009. Pollutant attenuation at the groundwater-surface water interface: A classification scheme and statistical analysis using national-scale nitrate data. Journal of Hydrology, 369(3-4), 392-402.

Storey, R., Fulthorpe, R., \& Williams, D., 1999. Perspectives and predictions on the microbial ecology of the hyporheic zone. Freshwater Biology, 41(1), 119-130.

Trauth, N., \& Fleckenstein, J. H., 2017. Single discharge events increase reactive efficiency of the hyporheic zone. Water Resources Research, 53(1), 779-798.

Trauth, N., Musolff, A., Knöller, K., Kaden, U. S., Keller, T., Werban, U., \& Fleckenstein, J. H., 2018. River water infiltration enhances denitrification efficiency in riparian groundwater. Water Research, 130, 185-199.

Welch, C., Cook, P. G., Harrington, G. A., \& Robinson, N. I., 2013. Propagation of solutes and pressure into aquifers following river stage rise. Water Resources Research, 49(9), 5246-5259.

Welch, C., Harrington, G. A., \& Cook, P. G., 2015. Influence of groundwater hydraulic gradient on bank storage metrics. Groundwater, 53(5), 782-793.

White, D. S., 1993. Perspectives on defining and delineating hyporheic zones. Journal of the North American Benthological Society, 12(1), 61-69.

\section{Hosted file}

HYP Figures.docx available at https://authorea.com/users/285309/articles/455990-hyporheicexchange-mechanism-driven-by-flood-wave 
Table 1 Model parameters involved in the simulation.

\begin{tabular}{lccl}
\hline Parameters & Symbol & Unit & Value \\
\hline Hydraulic conductivity & $K$ & $\mathrm{~m} / \mathrm{d}$ & 2.99 \\
$\underline{\text { Effective porosity }}$ & $n_{\mathrm{e}}$ & - & $\underline{0.35}$ \\
$\underline{\text { Specific storage }}$ & $S_{0}$ & $1 / \mathrm{m}$ & $\underline{0.000075}$ \\
$\underline{\text { Maximum saturation }}$ & $S_{\mathrm{s}}$ & - & $\underline{0.94}$ \\
Residual saturation & $S_{\mathrm{r}}$ & - & 0.146 \\
Retention curve fitting parameter & $\alpha$ & $1 / \mathrm{m}$ & 7.5 \\
Aperture Distribution Index & $n$ & - & 1.95 \\
\hline
\end{tabular}

*this table is originated from Liu et al. (2019). Underlined parameters are re-calibrated in this study due to the improvements of the model. 